Journal of Agricultural Extension

Vol. 12 (2) December, 2008

\title{
Issues for Agricultural Extension Policy in Nigeria
}

Koyenikan, M. J.

Projects Coordinating Unit (PCU)/Federal Ministry of

Agriculture and Water Resources (FMAWR),

Regional Office, P.M.B. 1210, Benin City.

Email: mkoyenikan@yahoo.com

\begin{abstract}
Agriculture is the bedrock of economic development in Nigeria. However, the development of the sector cannot be achieved without an efficient and effective extension system. Thus, there is the need for a well articulated and comprehensive Agricultural Extension Policy (AEP). It is against this background that the paper examines the content of agricultural extension sub-policy in the current Nigeria's Agricultural Policy with a view to establishing the need for a National Agricultural Extension Policy (NAEP). Issues in Extension Policy formulation; extension goals, approach and functions, subject matter, geographical coverage, target beneficiaries, organization, staffing, funding and stability were examined and how they could be addressed in the proposed AEP. The paper suggests as the goal; achievement of a well organized extension system for efficient and effective extension delivery in all aspects of sustainable agriculture and rural development to attain food security, poverty reduction, rural empowerment and environment management. It concludes with a summary of key recommendations for the proposed Agricultural Extension Policy. These include constituting a committee on NAEP to be chaired by the PS, FMAWR and the policy should make extension agenda farmer-driven and participatory. Also, decentralization of Nigerian agricultural extension system and its efficient coordination at various levels to ensure effectiveness and sustainability.
\end{abstract}

\subsection{INTRODUCTION}

Agricultural is important to the Nigerian economy as it engages about $70 \%$ of the labour force and contributes over $40 \%$ of the Gross Domestic product (GDP) (FMARD,2000). It provides food for the teeming population and raw materials for industries. The sector is faced with mirage of problems which militate against optimizing its potential. Some of the constraints include low productivity, poor marketing and distribution infrastructures, inadequate access to credit, weak extension services and inadequate database among others. An attempt to ameliorate the constraints by the Federal Government was the adoption of the Agricultural Policy for Nigeria in 1988 (FMARD, 2000).

The Nigeria Agricultural Policy provided the framework for implementation of programmes and guidelines for agricultural development. The broad objective was to attain self sustaining growth in all the sub-sectors of agriculture and realization of the structural transformation relevant for overall socio-economic development of rural areas (FMARD, 1988). This was expanded in the revised policy to include promoting 
farmer friendly Agricultural Policy that achieves food security, eradicates poverty, develops the rural economy and protects the environment (FMARD, 2000).

The objectives and strategies to achieve them as spelt out in the policy documents emphasize the importance of agricultural extension to the goal attainment of the agricultural sector. To achieve increased production and improved processing in all the sub-sectors of agriculture (crop, livestock, and fisheries), improvement of quality of life and promotion of environment friendly practices and other objectives require extension effort.

The new policy thrust expanded the broad objective according to FMARD (2000) to include;

Promoting farmer-friendly agricultural policy that achieves food security, eradicates poverty, develops the rural economy and protects the environment through;

- Creating the conducive macro-environment to stimulate greater private sector investment in agriculture,

- Rationalizing the roles of the three tiers of government in their promotional and supportive activities to stimulate growth;

- Reorganizing the institutional framework for government intervention in the sector,

- Articulating and implementing integrated rural development as a priority national programme to raise the quality of life of the rural people;

- Increasing agricultural production through increased budgetary allocation and promotion of the necessary developmental, supportive and service-oriented activities, opportunities;

- Increasing fiscal incentives to agriculture,

- Promoting increased use of agricultural machinery and inputs through favourable tariff policy.

This policy direction placed additional responsibilities on extension by including sustainable development components.

\subsection{Agricultural Extension in the Nigerian Agricultural Policy}

Agricultural extension brings about changes, through education and communication in farmers attitude, knowledge and skills. The role of agricultural extension involves dissemination of information, building capacity of farmers through the use of a variety of communication methods and help farmers make informed decisions. Sinkaye, (2005) equates help in extension to empowering all members of the farm households to ensure holistic development.

The Nigerian extension service is bedeviled by several problems as identified by Agbamu (2005). These include inadequacy and instability of funding, poor logistic support for field staff, use of poorly trained personnel at local level, ineffective agricultural research extension linkages, insufficient and inappropriate agricultural technologies for farmers, disproportionate Extension Agent: Farm Family ratio and lack of clientele participation in program development. Others are poor input supply, irregular evaluation of extension programmes and policy, institutional and programme instabilities of National agricultural extension systems. Some of the recommendations to improve the service are to make its content more relevant to farmers, alternative 


\section{Journal of Agricultural Extension}

Vol. 12 (2) December, 2008

sustainable financing option, well trained, and adequate staffing, and the use of participatory extension approach under stable policy and sustainable institutional arrangement.

Agricultural extension was addressed under support services in the Agricultural Policy under the heading "Agricultural technology Development and Transfer". The objective was "to teach rural people to raise their standard of living with minimum assistance and by their efforts" The document recognized that the extension system was plagued by administrative, manpower and financial problems. The strategies to adopt include;

- Provision of training facilities and infrastructures;

- Establishment of effective communication channels among research, extension and farmers;

- Effective utilization of extension service as agent for technology transfer;

- Establishment of demonstration farm and rural processing centres; and

- Encouragement of the private sector to invest in agricultural information dissemination.

The revised policy agrees with the first but emphasized roles and responsibilities of the 3 tiers of government in jointly financing agricultural extension. The document observed non integration of State Agricultural Development Programmes (ADPs) and State Ministries of Agriculture and Natural Resources (SMANR) extension interventions, weak Research Extension Farmer Input Linkage System (REFILS), poor feed- back from farmers to research, inadequate logistics and failure of Unified Agricultural Extension Service (UAES) to make much impact in fisheries and livestock. The policy stated that ADP and SMANR extension will be streamlined, through integration of both extension outfits, establishment of model farms, strengthening the extension service, use of demonstration, adoption of integrated production and pest management system, and encourage alternate extension providers.

The content is not explicit enough and vital issues were left out hence it will not be adequate to guide programme development and action plans for effective extension system. It is noteworthy the fact that FAMRD (2000) revealed that;

"the experience gained in the implementation of the agricultural policy over the years and the recent trends in agricultural development world wide have necessitated the formulation of more focused sub-sectoral policies. The most recent efforts in this direction are the: Land Resource Policy, National Cooperative Development Policy,

National Seed Policy and National Policy on Integrated Rural Development"

These according to the document are prelude to general review of the entire body of the national agricultural and rural development policy.

National Agricultural Extension Policy (NAEP) should also be considered as well. Formulation and implementation of National Agricultural Extension Policy as an instrument which will contribute to the attainment of National Agricultural Policy objective would be necessary considering the relevance of agricultural Extension to the goal and objectives of the agricultural policy. 


\subsection{Making a case for Agricultural Extension Policy (AEP) for Nigeria}

Government has responsibility for policy formulation, promulgation of regulations and initiation of programmes. The importance of AEP was recognized by FAO's Global Consultation on Agricultural Extension (GCAE), Swanson (1990) in Contado (1997).

It recommended that;

"all national governments should develop and periodically review their agricultural extension policy. This policy should include the goals of agricultural extension, the responsible agencies and personnel, the clientele to be served, the broad programmatic areas to be addressed and other relevant guidelines" Furthermore, that "the FAO in cooperation with the donor community, should engage in policy dialogue with national governments to stress the importance of agricultural extension in national agricultural development and the need to have an explicit, formally enacted, agricultural extension policy"

Eighteen (18 years) after the Global Consultation on Agricultural Extension (GCAE), the AESON Conference of 2007 saw the need for an AEP for Nigeria. The AEP is therefore overdue and there is need for Nigeria to join the league of progressive nations in this regard having experienced the ills of a directionless, scanty and unlegislated AEP. The time is now with dwindling public support, proliferation of donor supported, private and NGO extension programmes which are not coordinated. It is now time to act and be proactive

\subsection{ISSUES FOR CONSIDERATION IN THE PROPOSED AEP}

\subsection{Goal of Extension Policy:}

The goal of the AEP must align with that of the Agricultural policy. In this regard, the goal of the proposed AEP could be:

"To achieve a well organized extension system for efficient and effective extension delivery in all aspects of sustainable agriculture and rural development towards the attainment of food security, poverty reduction, rural empowerment and environment management".

Other issues in the AEP are expected to form the objectives or components to be addressed in order to achieve the stated goal.

\section{Specific Objectives of the Proposed AEP}

These include ensuring;

(i) Farmer driven and environment friendly extension;

(ii) The use of appropriate extension approach and methodologies;

(iii) Decentralization of the extension system and activities;

(iv) Extension support to all categories of farmers;

(v) Efficient and effective extension service delivery system;

(vi) Adequate training of extension personnel; and

(vii) Sustained funding of agricultural extension delivery. 


\subsection{Subject Matter Coverage}

Extension advice will be provided on all aspects of agriculture and environment (crops, livestock, fisheries, agro-forestry, post harvest enterprises and sustainable agricultural practices) and cross cutting issues such as nutrition and HIVIAIDS as well as malaria prevention, environment friendly practices e.g. (IPM), indigenous knowledge technologies (IKTs).

Needs of different clientele categories, gender, resource ownership, vulnerability will be taken into consideration. In essence, farmers' problems will dictate extension agenda and local resources will be utilized.

\subsection{Extension Approach and Functions}

Extension needs to go beyond technology transfer to developing skills and knowledge of farm families for sustainable agriculture and rural development. There should be paradigm shift from the Training and Visit (T\&V) which involves technology transfer and emphasizes individual contact to more participatory approach. There will be the need to adopt group approach to ensure effective use of limited resources; personnel, time and fund. The approach will ensure participation, ownership, inclusion and empowerment. More farmers will be reached and all gender categories could be catered for through participatory community planning (PCP).

Variety of extension methods will need to be used. Selection and use of appropriate methods in order to meet specific extension objectives with various categories of farmers will be necessary. They include (a) individual farm and home visits for follow up, (b) group methods: demonstrations to farmers groups, field days, (c) Mass Media to create awareness and reach large population at a time, (d) Farmers Trainings, and (g) Participatory methods in which extension staff work with farmers to analyze current situations and problems and determine appropriate action for self reliance (Pretty \& Volouche, 1997). Examples include RRA, PRA, Farmer field schools (FFS), IMP etc. These extension methods are the tools extension staff draw from, to address specific needs. Their use cannot be restricted but levels of emphasis may vary.

\subsection{Geographical Coverage}

This forms the basis for the operation of geopolitical and agro- ecological zones. Choice of communities for donor supported programmes, are usually politically motivated. Some programmes are based on comparative advantage of the area such as Root and tuber Expansion Programme (RTEP), Community Based Natural Resources Management Programme - Niger Delta (CBNRMP-ND) and National Fadama Development Project (NFDP). Other communities have to be developed as well in order to achieve broad based development. This is why statewide programmes like the ADPs need to be supported with adequate public funding, staffing and media support.

Decentralization of extension to lower tiers of government as stated in Nigeria's Agricultural Policy is necessary for planning, implementation, monitoring and evaluation of extension programmes at the local level. If LGs take responsibility for extension as the closest to the grass root, farmers' needs could be better met because the staff will be localized, conversant with the needs and would be able to facilitate extension activities more effectively. Every activity should reflect local needs 
e.g. training and mass media messages, and materials should be locally produced. Local action plans should be developed at the community level and passed upwards (bottom-up) as obtained in Fadama II and others.

It is also necessary to address comparative or otherwise advantages posed by natural resources in terms of production e.g. fisheries resources, potentials for fadama, forestry/tree crops, arable, livestock or even environmental degradation/hazards which might required control measures e.g. flooding, erosion, soil infertility, water pollution. This will ensure effective resource utilization, conservation and adequate sustenance of the environment.

\subsection{Target Beneficiaries}

Until recently, agricultural extension focused on male farmers but with Women in Agriculture (WIA) Programme of the ADPs since 1989, the trend has changed. Donor Supported Programmes have also been emphasizing gender mainstreaming and targeting of women, youths and the physically challenged (vulnerable groups) where necessary. This trend should be sustained or improved upon in the AEP. Contado (1997) estimated active population in agriculture for the world as $51 \%$ and for Africa $76 \%$ (FAO 1994). All gender categories need to be involved proportionately for equity and goal attainment.

All socio-economic strata and gender categories in the rural areas must be reached for sustainable Agriculture and Rural Development (SARD). However due to the high proportion of the small scale farmers they have to be targeted while not neglecting large and medium scale farmers. This will address issues such as continuity of farming as business, youth restiveness, unemployment, rural - urban migration and vices, direction of research for technology generation, provision of infrastructures, achievement of desired goals and cost effectiveness. Population characteristics and resource availability through good data base that are gender disaggregated would help to adequately target beneficiaries.

\subsection{Organization}

The organization of the extension system should be well spelt out in the AEP. This according to Contado (1997) affects the framework for the service, scope, magnitude and structure of the extension system, effectiveness and impact of the extension service. He identified centralized, decentralized, cooperative and pluralistic organization of extension with different degrees of involvement of National, State and Local Governments.

Nigerian extension is more or less the decentralized type but the Federal coordinates, States carry out extension programmes, manage and control activities and resources. As observed by Contado (1997), the pluralistic type of extension organization is emerging in many countries, this is true for Nigeria. This has to be reflected in the AEP because the need for extension service is high. Public, private and non governmental organizations implement agricultural extension programmes e.g. Oil Companies such as Shell Petroleum Development Company (SPDC), in the Niger Delta Region, Universities, agro-business firms, religious and farmers' organizations e.g. Farmers Development Union (FADU). As observed by Contado (1997) the geographical coverage, subject matter, clientele and standard of work of the organizations are not known. Their efforts are not coordinated. There is need 
therefore to have an inventory of publicly and privately funded extension programmes and continuous review of their activities at different levels. The already existing levels of coordination of the Extension System (PCU/ FMARD, 2004) should be made more effective by involving the relevant stakeholders. Six levels are involved;

1. Village/Field/Site Level: EAs, other extension service providers and farmers groups interact at field level to exchange and experience information and get farmers' needs,

2. Block/Local Government Level: Local/Site Management Committee chaired by Chairman of LG where project is located. Other members include ward councilors from participating LGAs, site field managers, specialists, Extension staff,

3. Zonal Level: The Zonal Manager is responsible for programme implementation. He should facilitate zonal level interactions among stakeholders in his zone for effective extension delivery,

4. State Level: The Agricultural Development Project Executive Committee (ADPEC) constitutes the steering committee at the state level. The chairman is the Governor or the State Commissioner for Agriculture. Other members are Commissioners for relevant ministries to Agriculture and Finance, Directors of RBDA and Research Institutes covering the state, PCU/NFRA Provides policy support and guidance on implementation,

5. Regional Level Coordination (Geopolitical) The Regional Offices of PCU/NFRA coordinates activities of states in their zones. This level has been weak over the years, it needs to be strengthened., and

6. National Coordination: PCU/NFRA has responsibility to coordinate, supervise and implement activities in collaboration with states technical management committees and ADPEC. The facilitation of coordination of efforts of stakeholders also falls on the agency.

There is need to develop close cooperation among extension agencies and formal research institutes, inputs, credits and marketing to provide farmers with efficient services. Feedback to research institutions and solution back to farmers through Research Extension Farmers Inputs Linkage System (REFILS) activities should be strengthened. Integration activities of stakeholders into the system should be addressed.

It will be the responsibility of the each of 5 Zonal REFILS Coordinating Research institutes and the 6 Regional Offices of PCU/NFRA to facilitate the process. Participation of all stakeholders in REFILS activities should be mandatory; annual Zonal workshops, Zonal steering Committee meetings, Monthly Technology Review Meetings (MTRMs), REFILs Stakeholders' Meetings, Planning workshops, Joint Scientific Field Evaluation (JSFE) and Fortnightly Trainings (FNTs). There is also the need to learn from the farmers' informal research, indigenous knowledge technologies (IKTs).

The extension service providers within the system need coordination to optimize the use of limited resources: personnel, funds and logistics to increase coverage within the system. This implies sharing of information and expertise among the agencies involved, and participation where appropriate in each other's extension activities and jointly organized ones. Agencies should complement each other for effectiveness of the system and enhanced service delivery to farmers. 
The AEP should assign the responsibilities for integration while coordination should be those of PCU/NFRA and the National Agricultural Council of Nigeria. This will ensure more impact; avoid duplication, confusion of clientele population and effective and efficient resource utilization and management.

\subsection{Staffing}

Considering the enormous functions and tasks of extension, technical competence and number of professional staff in the organization becomes crucial. The pre-service training must be adequately designed (Swanson, 1984) to cover the broad areas such as technical subject matter, communication and education, rural social systems and information about extension organization and operations. There should also be provision for staff development. This is particularly relevant because of shortage of extension staff vis-à-vis geographical coverage and farming population. The Extension Agent (EA): Farm Family (FF) ratio is very low with an average of $1 \mathrm{EA}$ to 1,722 FF in 2003 (Agbamu 2005). Recent figures for some states South East and South West states is as high as $-1: 1,590-7,000,1: 1,275-5,600$ compared to 1:1200, 1:800 1:1000, 1:252 and 1:500 for Indonesia, Mexico, Tanzania, Japan and South Korea respectively.

Malone (1984) staff training will help to maintain and upgrade competence of staff to perform tasks related to their jobs which aid the organization to reach its goals within its stated mission. Hence the need for capacity building from time to time, to solve basic production, management and marketing problems in crops, livestock, fisheries, forestry and cross cutting issues such as HIVIAIDS and nutrition. The AEP should support training of staff to be confident in solving farmer's problems and supply information needs of farmers. It should make provision for acquisition of skill by EAs/ Facilitators to deal with particular clients, women, youths. Current issues such as sustainable agriculture and rural development, participatory approaches (participatory learning and action approaches; PRA, RRA tools), comparative extension, best practices, community driven development, advances in technologies, problem diagnostic skills etc. Provision of funds, logistics support, motivation and training (overseas and higher education) will be necessary. In the proposed policy, training agenda and needs of EAs/Facilitators should be dictated by the requirements of farmers.

\subsection{Extension Funding}

GCAE (1990) noted that there is insufficient fund to provide adequate coverage of SARD for all groups of farmers especially resource - poor subsistent ones, women and youths in developing countries. There is need for substantial public funding of agricultural extension (AE) because of the benefits accruable. The general impression is that extension is expensive and wasteful; the criticism of T\&V but huge investment will be required to develop a country with over $70 \%$ involved in agriculture and who are rural based to attain broad based development. Contado (1997) suggests that ways to improve efficiency and reduce cost of public extension should be explored by stakeholders. This could be through encouraging group approach, but not neglecting individual contacts, use of mass media channel. Cost sharing by the 3 tiers of government, support from development partners, the private sector, NGOs and farmers organizations could be fixed as obtains in donor supported programmes. 
The Agricultural Development Fund should be effectively sourced and used as sustained fund as stated in Nigeria's Agricultural Policy.

\subsection{Stability}

The ADP is a veritable and formidable structure any sector could have to reach the grass-root. This structure should be maintained and sustained. It has stood the test of time, survived for close to 30 years. Various extension programmes in agricultural and rural development; NPFS, Fadama II \& III, RTEP, CBNRMD etc. and cross cutting issues like nutrition, HIVIAIDS and malaria have continued to be channeled through the structure.

The LGCs should take over at their respective block levels and be more responsive. The proportion of resources to provide; staff, fund logistics etc. should be stipulated in the AEP.

According to Contado (1997), AEP is expected to promote stability of extension system, must be flexible, responsive to all major groups of farm people and inclusive to allow public, private, NGOs to contribute fully to development (Swanson 1990 p.11). Frequent organizational changes within extension affect effectiveness and should be avoided.

Contado cited USA 1914 as having 80 years of Cooperative Extension Services Law, Japan 50 years and Thailand 40 years of following their extension policies respectively. Agricultural Extension is recognized as having contributed significantly to increased agricultural productivity and development in these countries.

Training and visit approach though criticized made its mark and due to its flexibility and adaptability, it could still be operated in areas where transfer of technology might be necessary to make impact in increasing production in specific areas or commodities. Community based participatory approaches are equally expensive and usually localized hence required outreach to other areas. A combination of approaches could be accommodated.

\subsection{CONCLUSION}

Agricultural extension is crucial to development in the agricultural sector and overall national development. Contado (1997) asserts that there is need to legislate Agricultural Extension Policy so that it will be well organized, financially stable for effectiveness and sustained impact. The fact that extension cuts across all other subsectors of agriculture demands that its coordination, funding, subject matter, staffing, geographical coverage and organization be guided by a framework in which its programmes and activities are implemented. Nigeria has to respond to the call of GCAE to formulate comprehensive and well articulated AEP. The need for paradigm shift from top - bottom transfer of technology (TOT) to more participatory approach which emphasize community driven development (CDD) and sustainable agriculture and rural development makes comprehensive and well articulated AEP a necessity. 
The following are key recommendations for the proposed AEP;

- AESON to collaborate with PCU/NFRA to facilitate government endorsing the setting up of high powered AEP committee to be chaired by PS FMAWR to commence action;

- The committee will review with farmers and other stakeholders; public private sector, NGOs, professionals and LG representatives the issues for the AEP;

- The AEP should be sustainable agricultural and rural development focused by adopting the Community Driven Development (CDD) approach, diversifying agricultural production, mainstreaming gender, addressing the environment and cross cutting issues such as nutrition, HIVIAIDS and others;

- Provision should be made for statewide coverage by public funding since community- based programmes are localized;

- Extension and research agenda must be based on farmers identified prioritized needs i.e. demand driven using PRA, RRA or other participatory approaches;

- There should be sustained financial support from the 3 tiers of government through a funding ratio and other stakeholders. There is need to explore the Agricultural Development Fund (ADF);

- There should be agro-ecological specialization and local planning of all activities e.g. action plans, training needs, media support etc to reflect local situations;

- Participation in REFILS activities should be mandatory for all agencies involved in the extension system at their respective levels for effective integration;

- Unification of Agricultural Extension Service (UAES) should be made more effective through better participation of non crops SMSs (fisheries, livestock, apiculture etc) in REFILS activities, MTRMs and FNT sessions.

- Adoption of combination of relevant approaches and use of variety of extension methods for effectiveness and to meet specific objectives;

- Activities of Extension Service providers in all sectors should be well coordinated at the 6 levels; field (village), block/ LG, Zonal, State, Regional and Federal levels.

- Extension should learn from farmers; promotion of indigenous knowledge technologies (IKTs) of farmers

- Emphasis should be on best, sustainable and environmental friendly practices;

- Continuous training of extension staff to face the challenges of their job in current technical skills and knowledge e.g. participatory community planning, PRA, RRA tools, subject matter areas, new advances in technologies, sustainable agriculture, best practices; integrated pest management, farmers' field school, IKTs, environmental-friendly practices etc. 
Some countries have formulated their AEP among which is the People's Republic of Bangladesh (Bangladesh Ministry of Agriculture, 1996). A NAEP is a necessity for Nigeria hence AESON should follow up this laudable initiative to logical and successful conclusion.

\section{References}

Agbamu, J. U. (2005) Problem and Prospects of Agricultural Extension Service in Development Countries in Agricultural Extension in Nigeria S. F. Afolayan (ed) Ilorin AESON, P. 159 - 169

Bangladesh Ministry of Agriculture (MA), (1996).New agricultural extension policy (NAEP). Government of the People's Republic of Bangladesh. p1- 11.

Contado, T. E. (1997) Formulating Extension Policy. In Improving Agricultural Extension: A reference manual Swanson et el Eds) Rome FAO

FMARD, (1988). Nigeria's Agricultural Policy. Federal Republic of Nigeria

Federal Ministry of Agriculture and Rural Development (2000) Agriculture in Nigeria: the New Policy Thrust

Malone, V. M. 1984 In-Service Training and staff development in Agricultural Extension: A reference manual Swanson B. (Ed) Rome, FAOAgricultural Extension: A reference manual Swanson B. (Ed) Rome, FAO

Pretty, J. N and S. D. Volouhe (1997): Using Rapid Rural Appraisal in Improving Agricultural Extension In Improving Agricultural Extension: A reference manual Swanson et el Eds) Rome FAO. P.47-57

Projects Coordinating Unit (PCU)/FMARD, (2004). Brief on Projects Coordinating Unit. P. 1-38

Swanson, B. (1984) Pre service Training. in Agricultural Extension: A reference manual Swanson B. (Ed) Rome, FAO

Sinkaiye, T. (2005), Agricultural Extension Participatory Methodologies and approaches in Agricultural Extension in Nigeria S. F. Afolayan (ed) Ilorin AESON, P. 220-233. 